\title{
Laser ablation of high-aspect-ratio hole arrays in tungsten for X-ray applications
}

\author{
Silvestre, Chantal M.; Hemmingsen, Jens H.; Dreier, Erik S.; Kehres, Jan; Hansen, Ole
}

Published in:

Microelectronic Engineering

Link to article, DOI:

10.1016/j.mee.2019.03.007

Publication date:

2019

Document Version

Peer reviewed version

Link back to DTU Orbit

Citation $(A P A)$ :

Silvestre, C. M., Hemmingsen, J. H., Dreier, E. S., Kehres, J., \& Hansen, O. (2019). Laser ablation of highaspect-ratio hole arrays in tungsten for X-ray applications. Microelectronic Engineering, 209, 60-65.

https://doi.org/10.1016/j.mee.2019.03.007

\section{General rights}

Copyright and moral rights for the publications made accessible in the public portal are retained by the authors and/or other copyright owners and it is a condition of accessing publications that users recognise and abide by the legal requirements associated with these rights.

- Users may download and print one copy of any publication from the public portal for the purpose of private study or research.

- You may not further distribute the material or use it for any profit-making activity or commercial gain

- You may freely distribute the URL identifying the publication in the public portal 


\title{
Laser ablation of high-aspect-ratio hole arrays in tungsten for $\mathrm{X}$-ray applications.
}

\author{
Chantal M. Silvestre ${ }^{a, b}{ }^{*}$, Jens H. Hemmingsen $^{a}$, Erik S. Dreier ${ }^{c}$, Jan Kehres ${ }^{d}$, Ole Hansen ${ }^{a}$ \\ ${ }^{a}$ DTU Nanotech, Technical University of Denmark, Ørsteds Plads 345, 2800 Kongens Lyngby, Denmark \\ ${ }^{b}$ DTU Danchip, Technical University of Denmark Ørsteds Plads 347, 2800 Kongens Lyngby, Denmark \\ ${ }^{c}$ Niels Bohr Institute, University of Copenhagen, Universitetsparken 5, 2100, Copenhagen, Denmark \\ ${ }^{d}$ DTU Physics, Technical University of Denmark, Fysikvej, building 344, 2800 Kongens Lyngby, Denmark
}

\author{
Keywords: \\ High aspect ratio gratings \\ Laser ablation \\ Medical imaging \\ Phase-contrast imaging \\ Tungsten gratings \\ X-ray optics
}

\begin{abstract}
A B S T R A C T
Periodic two-dimensional tungsten X-ray optical gratings were fabricated using a combination of pico-second laser ablation and wet chemical etch. A $200 \mu \mathrm{m}$ thick cold-rolled sheet of tungsten $(99.97 \%)$ was used as base material for the fabrication of a $1.5 \times 1.5 \mathrm{~cm}^{2}$ periodic grating with an array of circular holes of approximately 12:1 aspect ratio. The laser parameters were optimized to obtain through-hole diameters slightly smaller than the desired final dimension. Subsequent wet etching was used to precisely control the diameter of throughholes. The through-hole profile was characterized using scanning electron microscopy (SEM) and showed a slight conical shape with a slope of $1.3 \%$. The two-dimensional tungsten absorption grating was successfully tested in an X-ray phase-contrast imaging setup. The method has proven to have some relevant benefits, such as good reproducibility and fairly easy fabrication due to few manufacturing steps.
\end{abstract}

\section{Introduction}

X-ray absorption imaging has been used extensively in medical diagnosis since its discovery in the late 19th century. Today, this form of imaging is widely applied also to other areas of research and technology, such as airport security, food industry or laboratory research equipment [1-3]; making it a valuable imaging technique. While X-ray absorption imaging gives high contrast images with absorbing materials like bones and metal, it has severe limitations when imaging weakly absorbing heterogeneous samples. In these cases, it becomes difficult to differentiate between two similar media, and thus the overall contrast of the image is significantly reduced. An alternative to overcome this limitation is to take advantage of the dispersive contribution $\delta$ of the refractive index $(n=1-\delta+\mathrm{i} \beta)$ of the sample material. Conventional X-ray absorption imaging relies exclusively on the absorptive contribution $\beta$ of a material, and ignores the dispersive aspect. However, for weakly absorbing materials, the dispersive contribution can be several order of magnitude higher that of the absorptive contribution. The dispersion causes a phase-shift of the transmitted light, which once recorded, can be used to enhance the contrast of the final image. The method relies on measurement of the deflection of light in the propagation direction caused by the refraction of the object being imaged as illustrated in

Fig. 1.

During the last fifteen years, several phase-contrast imaging techniques, using X-ray laboratory sources, have shown a potential for circumventing the limitations of standard absorption imaging; hence allowing the discrimination between similar tissues using clinical-size setups [4-6]. The main optical elements of these setups are the gratings, whose precision and high aspect ratio (HAR) play a significant role in the final image quality.

To ensure a high X-ray contrast image, the gratings are made of heavy absorbing material (high atomic number $Z$ and high density $\rho$ ), with a high aspect ratio structure (often above 10:1). In our setup, the grating pattern is a periodic two-dimensional grid of $12 \mu \mathrm{m}$ holes with a period of $100 \mu \mathrm{m}$ over an active area of $1.5 \times 1.5 \mathrm{~cm}^{2}$, which acts as an absorbing mask. In the state-of-the-art fabrication process of these absorption gratings, gold is often preferred as the heavy absorber element. Gold is an almost ideal absorber for X-rays and can easily be electroplated. In these cases, the metal is micro-casted or electroplated into periodic scaffold templates, prepared using deep reaction ion etching (DRIE) or wet etching of silicon [7-9].

\footnotetext{
* Corresponding author at : Technical University of Denmark, 2850 Kongens Lyngby, Denmark.

E-mail address: chasil@dtu.dk
} 


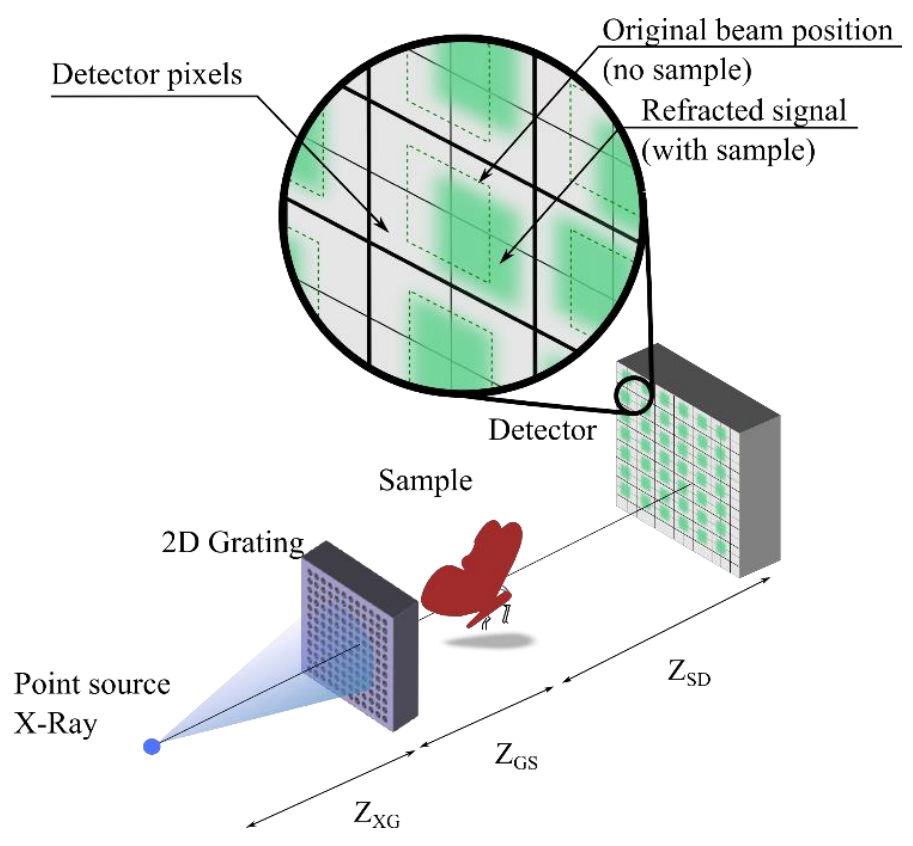

Fig. 1. - Schematic of an X-ray phase-contrast imaging setup using a single two-dimensional periodic array grating. The X-rays are deflected from their original propagation direction which creates an intensity shift on the detector pixels.

Other fabrication approaches using a combination of lithography, electroplating and moulding (LIGA) processes have also been reported $[10,11]$. However, to achieve a complete absorber grating with these conventional methods, either several fabrication steps or costly steps (such as synchrotron radiation based lithography in the case of LIGA) must be performed; hence, increasing the complexity, and the cost of the final device and limiting the opportunity for mass production.

In this work, we propose to use tungsten as an alternative to gold. The density and atomic number of tungsten $\left(19.25 \mathrm{~g} / \mathrm{cm}^{3}\right.$, 74) is comparable to those of gold $\left(19.3 \mathrm{~g} / \mathrm{cm}^{3}, 79\right)$ and thus, similar HAR holes are required to get comparable X-ray absorption contrast as shown in Table 1, where key parameters for potential absorber materials are listed. For good X-ray absorbers, both the atomic number and the density should be high. Table 1 shows that approximately $205 \mu \mathrm{m} \mathrm{W}$ will absorb $90 \%$ of the incoming intensity of a $50 \mathrm{keV}$ beam. To achieve a similar absorption only $167 \mu \mathrm{m}$ of gold $(\mathrm{Au})$ is required, however at significantly larger material costs when considering large area gratings. The same applies for Iridium (Ir) and Platinum $(\mathrm{Pt})$ which are rare and expensive materials. Cheaper materials like Tantalum $(\mathrm{Ta})$, Bismuth $(\mathrm{Bi})$ and Lead $(\mathrm{Pb})$ require larger thicknesses to achieve similar absorption, thus increasing the already difficult-to-achieve high aspect ratio of the grating. Patterning directly on a tungsten substrate allows for reducing the number of fabrication steps. The fabrication of tungsten gratings for X-ray optical elements using reactive ion etching has previously been reported [12,13]. However, this technique is, to our knowledge, limited to aspect ratios lower than 10 in tungsten thin films.

In order to pattern higher aspect ratio holes in tungsten we use a pico-seconds pulsed laser which illuminates the substrate at well-defined spots. By using laser ablation of tungsten we can pattern deeper holes and obtain larger aspect ratios. Ultra-short pulse lasers have already shown the ability to micromachine a wide range of metals and ceramics with a high degree of precision [14-16]. In our fabrication process, each pulse removes some material until a through-hole of a few micrometres in radius is formed. The through-hole is then widened to the desired diameter by wet chemical etching. Laser ablation of tungsten is a serial fabrication process which prevents high throughput and has a lower pattern resolution, as compared to conventional photolithography methods. However, this presented method has the advantage of requiring only very few processes steps, uses a cheaper material and does not use hazardous chemicals such as gold cyanide, which is the preferred electrolyte for Au plating; less harmful electrolytes exists but they suffer from poor shelf life. Furthermore, since the tungsten hole grating is a single material structure it might be easier to curve the grating to the radius of curvature needed to overcome the natural beam divergence of the light source in case a larger field of view is desirable. 
Table 1. - Properties of common X-ray absorber metals. The atomic number $Z$, the atomic weight $A$, and the mass density $\rho$, the attenuation length $L_{50 \mathrm{ke}}$ (1/e attenuation) as well as the required absorber thickness $d_{90 \%}$ for $90 \%$ attenuation at $50 \mathrm{keV}$ are listed. Values were calculated using ref. [17]. All elements are assumed pure.

\begin{tabular}{|c|c|c|c|c|c|}
\hline \multirow[t]{2}{*}{ Element } & \multirow{2}{*}{$\begin{array}{c}\text { Atomic } \\
\text { number } \\
\quad Z\end{array}$} & \multirow{2}{*}{$\begin{array}{c}\text { Atomic } \\
\text { weight } \\
A\end{array}$} & \multirow{2}{*}{$\begin{array}{c}\text { Density } \\
\rho \\
\left(\mathrm{g} / \mathrm{cm}^{3}\right)\end{array}$} & \multicolumn{2}{|c|}{ At $50 \mathrm{keV}$} \\
\hline & & & & $\begin{array}{l}\text { Attenuation } \\
\text { length }(\mu \mathrm{m})\end{array}$ & $\begin{array}{l}\text { Thickness } \\
d_{90 \%}(\mu \mathrm{m})\end{array}$ \\
\hline W & 74 & 183.84 & 19.25 & 89.0 & 205 \\
\hline $\mathrm{Au}$ & 79 & 196.97 & 19.30 & 72.4 & 167 \\
\hline $\mathrm{Ta}$ & 73 & 180.95 & 16.65 & 107.4 & 247 \\
\hline $\mathrm{Ir}$ & 77 & 192.22 & 22.56 & 68.5 & 158 \\
\hline $\mathrm{Pt}$ & 78 & 195.08 & 21.45 & 69.1 & 159 \\
\hline $\mathrm{Pb}$ & 82 & 207.20 & 11.34 & 114.0 & 262 \\
\hline $\mathrm{Bi}$ & 83 & 208.98 & 9.78 & 127.6 & 293 \\
\hline
\end{tabular}

\section{Material and methods}

The base materials for the grating were $10 \times 10 \mathrm{~cm}^{2}$ cold-rolled sheets of tungsten ( $99.97 \%$ from Plansee AG, Germany) with thicknesses of $200 \pm 35 \mu \mathrm{m}$ and $50 \pm 6 \mu \mathrm{m}$, respectively. The sheets were first diced in $2 \times 2 \mathrm{~cm}^{2}$ chips for this study. The thermal ablation of the pattern was carried out using a Nd:YVO picosecond laser from Lumentum Operations LCC, mounted in a microSTRUCT vario system (3D Micromac AG, Germany). The system generates pulses at a wavelength of $1064 \mathrm{~nm}$ with a pulse duration of $10 \mathrm{ps}$. The wavelengths of $532 \mathrm{~nm}$ and $355 \mathrm{~nm}$ are obtained by a second and third-harmonic generator. In this study, only the $355 \mathrm{~nm}$ wavelength was used since it exhibits the smallest spot size, and allows for the highest resolution. The beam diameter $\left(2 w_{0}\right)$ at $1 / \mathrm{e}^{2}$ of the Gaussian beam profile was evaluated using the method described by J. M. Liu [18]. The details of the laser characteristics and process parameters used are reported in Table 2.

Table 2. - Laser characteristic and process parameters

\begin{tabular}{|c|c|c|}
\hline \multicolumn{3}{|c|}{ Laser characteristics } \\
\hline Pulse duration & \multicolumn{2}{|l|}{$10 \mathrm{ps}$} \\
\hline Repetition rate & \multicolumn{2}{|l|}{$200 \mathrm{kHz}$} \\
\hline Wavelength & \multicolumn{2}{|l|}{$355 \mathrm{~nm}$} \\
\hline Beam diameter at $1 / \mathrm{e}^{2}\left(2 w_{0}\right)$ & \multicolumn{2}{|c|}{$10 \pm 0.9 \mu \mathrm{m}$} \\
\hline Effective focal length & \multicolumn{2}{|c|}{$100 \mathrm{~mm}$} \\
\hline Beam shape & \multicolumn{2}{|c|}{ Gaussian } \\
\hline Beam quality & \multicolumn{2}{|c|}{$\mathrm{M}^{2}<1.3 \mathrm{TEM}_{00}$} \\
\hline \multicolumn{3}{|c|}{$\begin{array}{c}\text { Process parameters } \\
\end{array}$} \\
\hline Tungsten thickness & $200 \mu \mathrm{m}$ & $50 \mu \mathrm{m}$ \\
\hline Average output power & $4 \mathrm{~W}$ & $0.4 \mathrm{~W}$ \\
\hline Fluence & $50 \mathrm{~J} / \mathrm{cm}^{2}$ & $5 \mathrm{~J} / \mathrm{cm}^{2}$ \\
\hline Repetition rate & \multicolumn{2}{|c|}{$200 \mathrm{kHz}$} \\
\hline Number of pulse per hole & 10,000 & 1400 \\
\hline $\begin{array}{l}\text { Total processing time } \\
\text { (per grating) }\end{array}$ & $10 \mathrm{~h}$ & $1.5 \mathrm{~h}$ \\
\hline
\end{tabular}

The tungsten $2 \times 2 \mathrm{~cm}^{2}$ chip was placed on the vacuum chuck of the tool under ambient atmosphere and pressure, and the focal position of the laser was set at the surface of the workpiece using the embedded camera. During processing, the sample remained stationary while the beam was guided in the $x-y$ direction using piezo-mounted mirrors as illustrated in Fig. 2a. The desired pattern was created using a Visual Basic Script (VBS), and consisted of a matrix of 150 x 150 dots spaced with a pitch of $100 \mu \mathrm{m}$ and aligned to the centre of the chip. For ultra-short pulses, such as from pico- and femtosecond lasers, the pulse length is shorter than the time required to heat the material ion lattice. In this case, the material is vaporized in the form of droplets and ejected out of the material by the pressure produced in the overheated liquid formed at the interface between the plasma and the metal as illustrated in Fig. 2b [19]. 


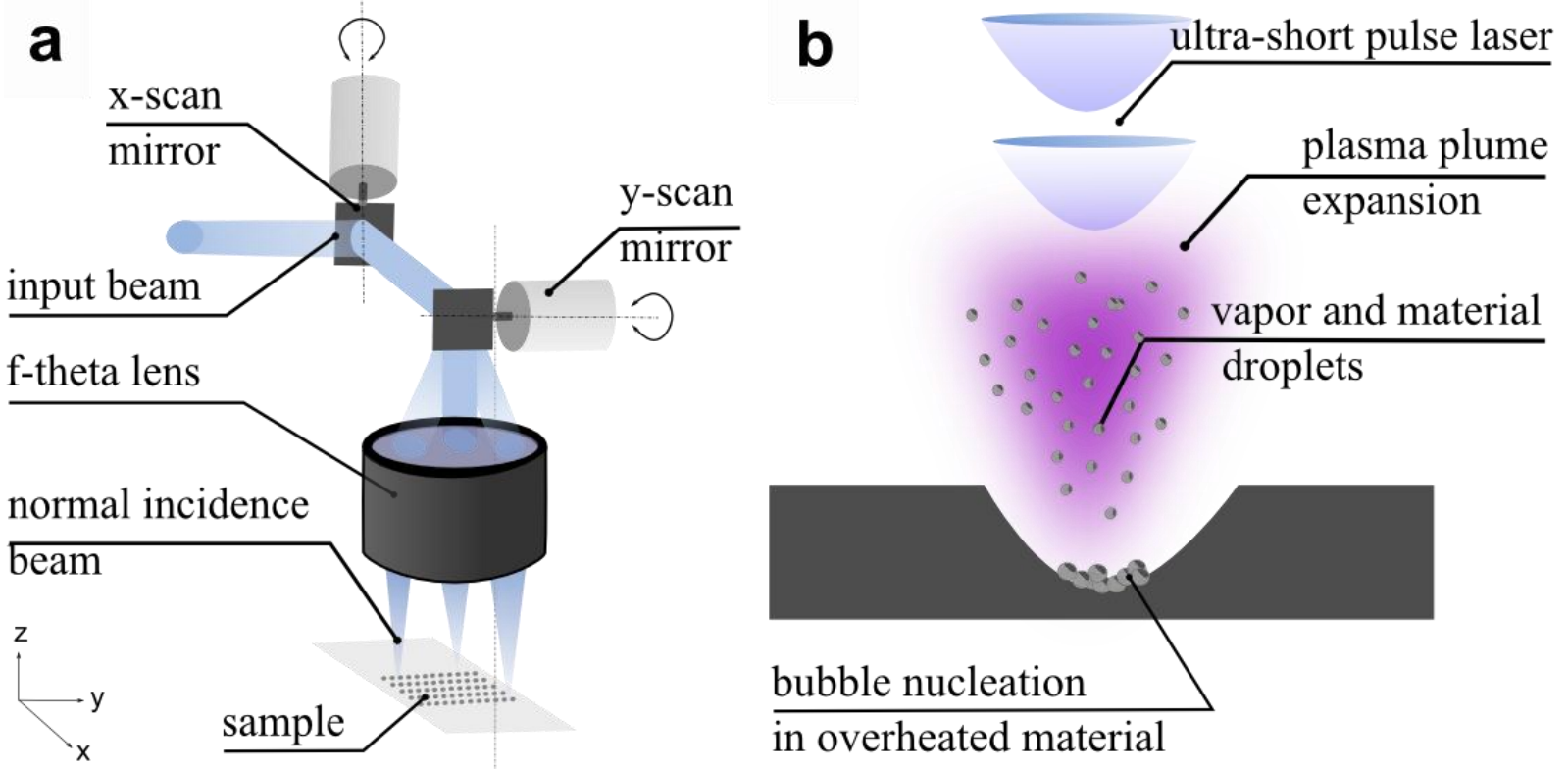

Fig. 2. - (a) Schematic of the laser beam focused through a telecentric f-theta lens and controlled by piezo-mounted mirrors. The beam always illuminates the substrate at normal incidence. (b) Illustration of the ultra-short pulse laser ablation mechanism.

Although the diameter of the spot size (Fig. 3a) at $1 / \mathrm{e}^{2}(13.5 \%)$ of the intensity is $10 \mu \mathrm{m}$, it was possible to obtain throughholes with diameters from 2 to $8 \mu \mathrm{m}$ by reducing the intensity as illustrated in Fig. 3b. The removal of material takes place when the incident energy density of the beam is larger than the ablation threshold of the material. Thus, reducing the peak intensity to a value near the ablation threshold allows material removal while insuring opening diameters below the beamwidth. However, reducing the intensity also affects the ablation rate, and therefore a trade-off between processing time and resolution has to be struck.

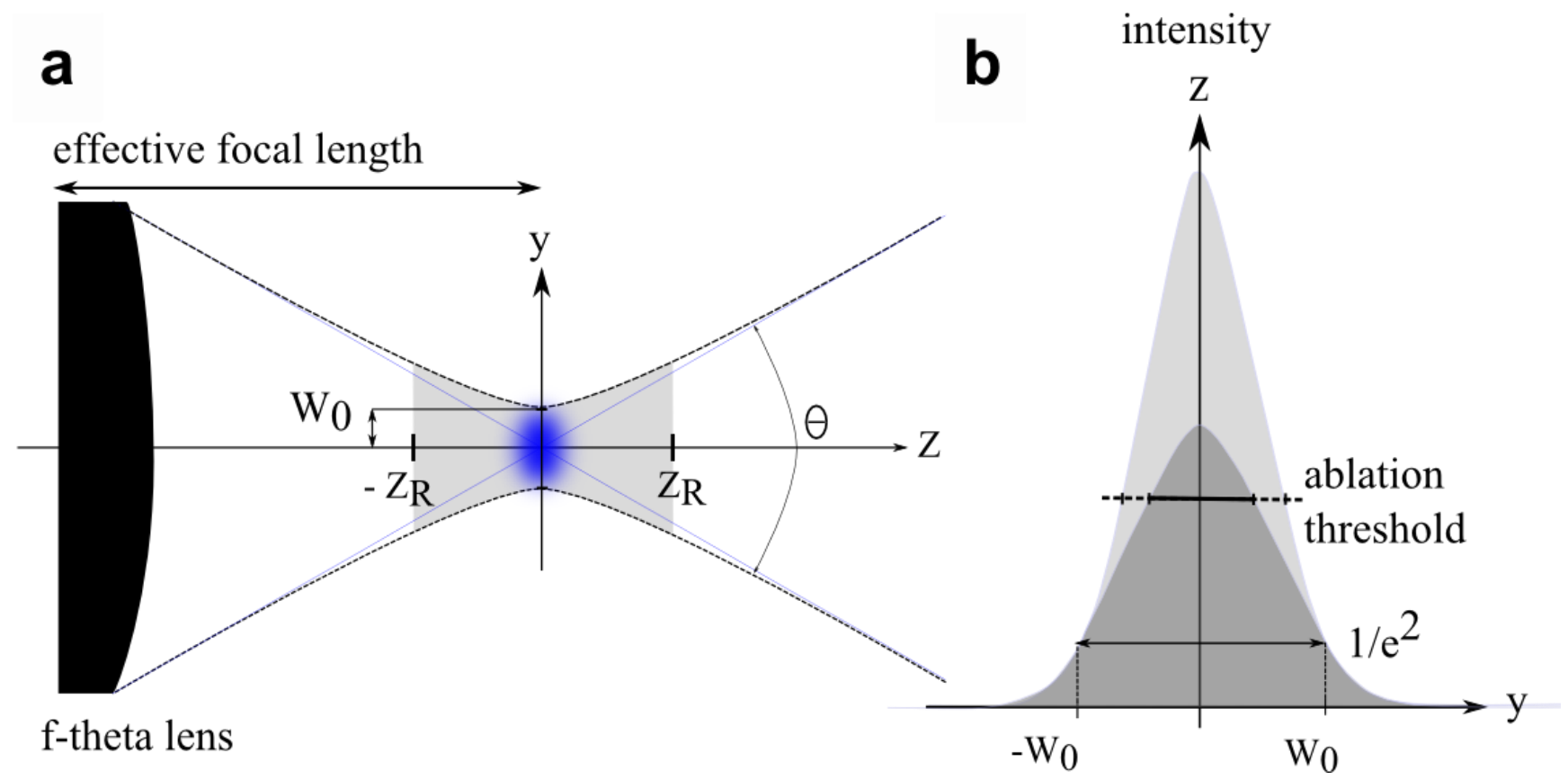

Fig. 3. - (a) Gaussian beam focused at the effective focal length with the divergence $\theta$, the beam size at $1 / \mathrm{e}^{2} w_{\mathrm{o}}$, and the Rayleigh distance $Z_{\mathrm{R}}$ (b) Illustration of the Gaussian beam cross-section for two different intensities compared to the ablation threshold.

Preliminary experiments verified that both the size and shape of the ablated material were affected by the beam power, the number of pulses as well as the laser repetition rate, thus accurate control of the through-hole diameter by controlling the 
beam intensity proved difficult. Moreover, the holes were often obstructed by re-deposited material consisting of non-volatile tungsten containing particles. The re-deposition of material during laser ablation also proved difficult to control and impossible to eliminate completely. To overcome these problems, we chose to combine laser ablation of through-holes (with diameters below target) with a wet chemical etching for removal of re-deposited material as well as fine tuning of the throughhole diameter. This approach was crucial for achieving well-controlled through-hole diameter and obstruction free throughholes and thus high signal-to-noise ratio (SNR) during X-ray imaging. Wet chemical etching for removal of re-deposits and widening of through-holes was done in an aqueous solution of 1:2 mixture of $\mathrm{NH}_{4} \mathrm{OH}$ (29\% by weight of $\mathrm{NH}_{3}$ in water) and $\mathrm{H}_{2} \mathrm{O}_{2}$ at $20{ }^{\circ} \mathrm{C}$ in an ultrasonic bath. The tungsten etch rate in this solution was measured to $0.5 \pm 0.3 \mu \mathrm{m} / \mathrm{min}$, which allows for decent control of the final through-hole diameter by timed wet etching. An increase in temperature to $40{ }^{\circ} \mathrm{C}$ revealed an etch rate of $1.1 \pm 0.2 \mu \mathrm{m}$.

\section{Results and discussion}

Fig. 4 illustrates a hole filled with redeposited material before and after chemical cleaning/etching at $40{ }^{\circ} \mathrm{C}$. The holes in this sample were made using 1400 pulses per hole on a $50 \mu \mathrm{m}$ thick tungsten foil. Redeposited material was not visible in all holes, and could also be trapped deep within the through-hole itself. Dark-field optical microscopy images (not shown here) easily revealed whether the holes were clear of redeposited material or not. Note, since the holes are not perfectly circular, the diameter of the circumscribed circle is reported (yellow dashed circles in Fig. 4). Evaluation of the aspect ratio for the 50 $\mu \mathrm{m}$ thick sample was made using the largest diameter of the through-hole, namely the entrance hole. The average entrance diameter of the drilled hole is $2.7 \pm 0.4 \mu \mathrm{m}$ which leads to an aspect ratio of $18.5: 1$, however a considerable amount of redeposited material was trapped in most of the holes and thus cleaning was necessary.
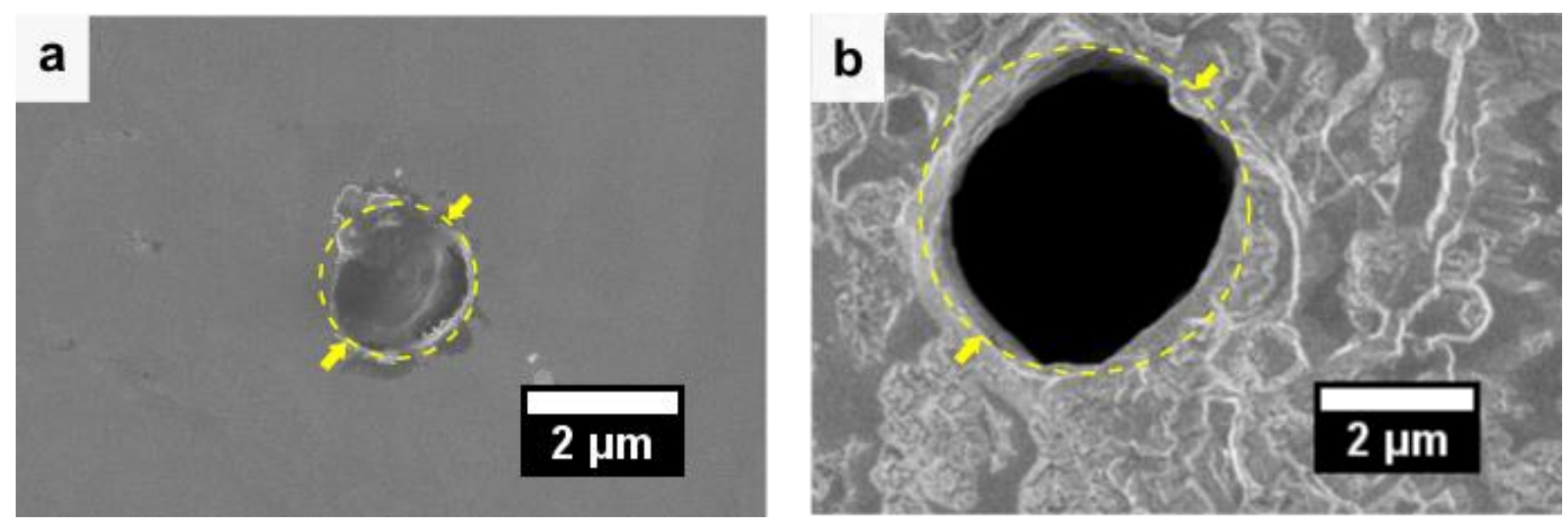

Fig. 4. - Example of an exit through-hole made in $50 \mu \mathrm{m}$ thick bulk tungsten. a) Redeposited material inside the hole before cleaning/widening. $\varnothing 2.05$ $\mu \mathrm{m}$. b) Same hole after cleaning/widening using $40{ }^{\circ} \mathrm{C}$ wet chemical etching. $\varnothing 4.40 \mu \mathrm{m}$

To further characterize the profile and aspect ratio of the ablated holes, we produced a similar sample using the same fabrication parameters, but now in a $200 \mu \mathrm{m}$ thick tungsten sheet. The sample used for the characterization was an array of $80 x 50$ holes with $100 \mu \mathrm{m}$ pitch and was subsequently diced diagonally through the array of holes in order to increase the probability to have a number of holes diced through the middle. The dicing step was done using an automatic dicing saw (Disco Dicer DAD321) and imaged using scanning electron microscopy (SEM). To allow for a clean image of the crosssection, the sample underwent a short $30 \mathrm{~s}$ cleaning in the etch solution at $20^{\circ} \mathrm{C}$ in order to remove the redeposited material without influencing the overall shape of the holes too much. In total, 3 holes along the diagonal dicing line were cut in their middle and they allowed for a measurement of the side-wall profile. The results, illustrated in Fig. 5a,b, reveal a conical shape of the hole throughout the thickness, with a slope of $1.3 \pm 0.2 \%$. Due to the nature of the cold-rolled tungsten foil fabrication, the top layers of the metal de-laminated during the dicing process. To evaluate the aspect ratio we used the diameter of the larger entrance holes prior to dicing. Since the holes are not completely circular, circumscribed circles were fitted to SEM images of the holes on the top of the samples. The average diameter of the entrance holes was $15.7 \pm 0.6 \mu \mathrm{m}$ which gives an aspect ratio of 12.7:1. The exit holes show an average diameter of $9.4 \pm 0.3 \mu \mathrm{m}$, which is in agreement with the measured slope after dicing. 

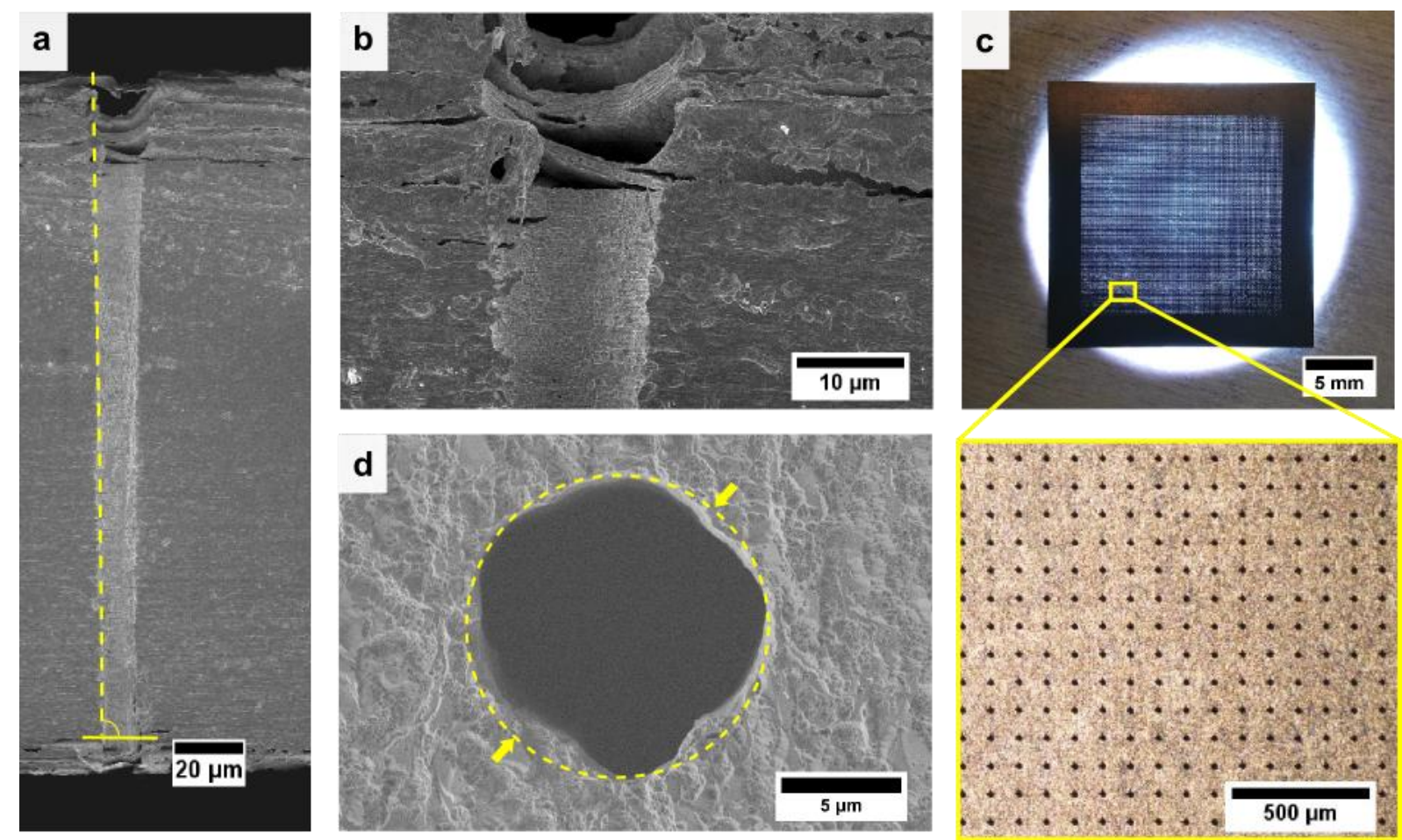

Fig. 5. - (a) Cross-section of a through-hole with aspect ratio 12.7:1 (b) Zoom on the conical top part of the hole. The dicing process de-laminated the topmost layers of the cold rolled laminated tungsten (c) Photograph of a final $1.5 \times 1.5 \mathrm{~cm}$ grating $(h=200 \mu \mathrm{m}, p=100 \mu \mathrm{m}, \emptyset=12.3 \mu \mathrm{m}$, aspect ratio 9.7:1) with micrograph close view on the active area. (d) Close view of an exit hole with fitted circumscribed circle. Average diameter of the exit holes: $12.3 \pm$ $0.1 \mu \mathrm{m}$.

Finally, to verify the ability of the tungsten grating to perform X-ray phase-contrast imaging, we tested a $h=200 \mu \mathrm{m}$ thick tungsten grating of $1.5 \times 1.5 \mathrm{~cm}^{2}$ active area (Fig. $5 \mathrm{c}$ ), with exit holes of diameter $\varnothing=12.3 \pm 0.1 \mu \mathrm{m}$ (Fig. $5 \mathrm{~d}$ ), and a chosen pitch of $p=100 \mu \mathrm{m}$. A series of samples were imaged using a single mask phase contrast imaging setup, as illustrated in Fig. 1 and described in [20] using a tungsten X-ray source operating at $50 \mathrm{kV}$. The technique uses the single absorption tungsten mask to cut the X-ray beam into multiple beam-lets (micron size X-ray beams). The sample affects the beam-lets through a reduction of their intensity due to absorption, a shift in position due to refraction, and broadening of the beam-lets intensity distribution due to X-ray scattering. By identifying each beam-lets photon distribution, it is possible to obtain a traditional absorption image, a phase contrast image (refraction), and a dark field image (scattering) of the sample in a single acquisition. The beam-lets intensity distribution is analyzed at the X-ray detector, by using single photon counting techniques described in ref. [20]. An example of an imaged moth is shown in Fig. 6. Here an absolute 2D differential phase-contrast image is compared to a standard absorption image taken with the same X-ray dose, and the improvement in image quality with phase contrast imaging is striking. Whether this method is comparable to that of gold electroplated gratings, with regards to image quality is subject to further investigations. The small variations in the wall profile of the holes, which are seen in the SEM images, were not observed to affect the final X-ray phase contrast images. It is estimated that the small contribution to the final beam-let intensity distribution measured on the detector from these variations is insignificant compared to the effect of the X-ray source spot size $(\sigma \sim 5 \mu \mathrm{m})$, and the non-uniform detector response described in ref. [20]. Nevertheless, this experiment demonstrates that laser ablation of tungsten is a viable technology for the manufacturing of HAR microstructures with the aforementioned dimensions. 

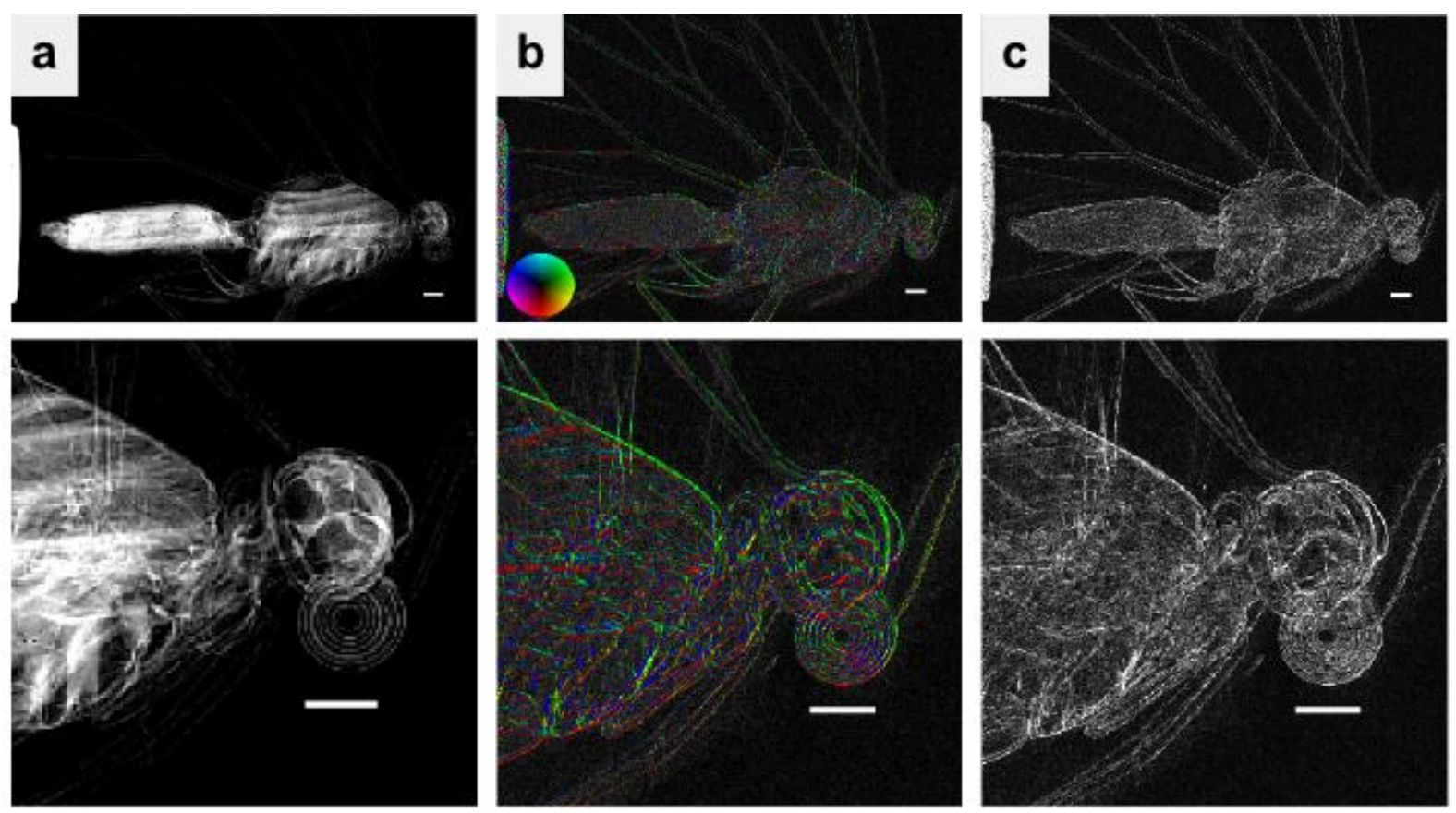

Fig. 6. - X-ray image of a moth acquired with a tungsten target X-ray source operating at $50 \mathrm{kV}$. a) Absorption image. b) Directional differential phase contrast (HSV). c) Absolute differential phase contrast image. Scale bar $1 \mathrm{~mm}$.

\section{Conclusion}

Our experiment has demonstrated the successful fabrication of two-dimensional $1.5 \times 1.5 \mathrm{~cm}^{2}$ periodic tungsten gratings using a combination of pico-second pulse laser ablation and chemical etch. Through-holes with a pitch of $100 \mu \mathrm{m}$ and diameter of $12.3 \mu \mathrm{m}$ were successfully micro-structured with an aspect ratio of 12.7:1 in $200 \mu \mathrm{m}$ thick bulk tungsten foils. The diameter of the holes was fine-tuned using a chemical etch solution based on hydrogen peroxide and ammonium hydroxide. We characterized the profile of the periodic pattern using electron microscopy and tested the grating on a phasecontrast imaging system. The characterization of cross-sectioned holes demonstrated a side wall slope of $1.3 \pm 0.2 \%$. The experimental X-ray images obtained showed a large amount of detail that could not be resolved with standard absorption Xray imaging. The reported results open the way to a simple method to pattern high aspect ratio holes in bulk tungsten. We are convinced that, despite the long processing time this method is nonetheless a viable method for creating absorbing gratings for X-ray phase-contrast imaging without the use of any hazardous or expensive wet chemical processes. Furthermore, we consider that the possibility to curve a tungsten grating to a preferred radius of curvature can pave the way for larger field of view gratings without the need of tiling smaller gratings together.

\section{Acknowledgement}

The authors acknowledge the Innovation Fund Denmark for its financial contribution.

\section{REFERENCES}

[1] A.O. Alberto Astolfo, Marco Endrizzi, Benjamin Price, Ian Haig, The first large area, high x-ray energy phase contrast prototype for enhanced detection of threat object in baggage screening, Proc. SPIE 9995 (2016) 999505-1-999505-7. doi:10.1117/12.2239556. quantitative studies of heat induced structural changes in meat, Meat Sci. 100 (2015) 217-221. doi:10.1016/j.meatsci.2014.10.009. 
96. doi:10.1016/j.ifset.2013.11.003.

[4] X. Li, H. Gao, Z. Chen, L. Zhang, X. Zhu, S. Wang, W. Peng, Diagnosis of breast cancer based on microcalcifications using grating-based phase contrast CT, Eur. Radiol. 28 (2018) 3742-3750. doi:10.1007/s00330-017-5158-4.

[5] F. Krejci, J. Jakubek, M. Kroupa, Hard x-ray phase contrast imaging using single absorption grating and hybrid semiconductor pixel detector, Rev. Sci. Instrum. 81 (2010) 113702. doi:10.1063/1.3499372.

[6] F. Pfeiffer, M. Bech, O. Bunk, P. Kraft, E.F. Eikenberry, C. Brönnimann, C. Grünzweig, C. David, Hard-X-ray dark-field imaging using a grating interferometer, Nat. Mater. 7 (2008) 134-137. doi:10.1038/nmat2096.

[7] L. Romano, J. Vila-Comamala, M. Kagias, K. Vogelsang, H. Schift, M. Stampanoni, K. Jefimovs, High aspect ratio metal microcasting by hot embossing for X-ray optics fabrication, Microelectron. Eng. 176 (2017) 6-10. doi:10.1016/j.mee.2016.12.032.

[8] C. David, J. Bruder, T. Rohbeck, C. Grünzweig, C. Kottler, A. Diaz, O. Bunk, F. Pfeiffer, Fabrication of diffraction gratings for hard X-ray phase contrast imaging, Microelectron. Eng. 84 (2007) 1172-1177. doi:10.1016/j.mee.2007.01.151.

[9] S. Znati, N. Chedid, H. Miao, L. Chen, E.E. Bennett, H. Wen, Electrodeposition of gold to conformally fill high-aspect-ratio Nanometric silicon grating trenches: a comparison of pulsed and direct current protocols, J. Surf. Eng. Mater. Adv. Technol. 05 (2015) 207-213. doi:10.4236/jsemat.2015.54022.

[10] J. Mohr, T. Grund, D. Kunka, J. Kenntner, J. Leuthold, J. Meiser, J. Schulz, M. Walter, High aspect ratio gratings for X-ray phase contrast imaging, AIP Conf. Proc. (2012) 41-50. doi:10.1063/1.4742267.

[11] J. Meiser, M. Willner, T. Schröter, A. Hofmann, J. Rieger, F. Koch, L. Birnbacher, M. Schüttler, D. Kunka, P. Meyer, A. Faisal, M. Amberger, T. Duttenhofer, T. Weber, A. Hipp, S. Ehn, M. Walter, J. Herzen, J. Schulz, F. Pfeiffer, J. Mohr, Increasing the field of view in grating based X-ray phase contrast imaging using stitched gratings, J. Xray. Sci. Technol. 24 (2016) $379-388$. doi:10.3233/XST-160552.

[12] F. Delachat, B. Le Drogoff, C. Constancias, S. Delprat, E. Gautier, M. Chaker, J. Margot, Fabrication of high aspect ratio tungsten nanostructures on ultrathin c-Si membranes for extreme UV applications, Nanotechnology. 27 (2015) 025304. doi:10.1088/09574484/27/2/025304.

[13] W. Chu, K.W. Foster, L.M. Shirey, K.W. Rhee, J. Kosakowski, I.P. Isaacson, D. McCarthy, C.R. Eddy, E.A. Dobisz, C.R.K. Marrian, M.C. Peckerar, Reactive ion etching of high-aspect-ratio $100 \mathrm{~nm}$ linewidth features in tungsten, Appl. Phys. Lett. 64 (1994) 2172-2174. doi:10.1063/1.111666.

[14] A. Ancona, F. Röser, K. Rademaker, J. Limpert, S. Nolte, A. Tünnermann, High speed laser drilling of metals using a high repetition rate, high average power ultrafast fiber CPA system, Opt. Express 16 (2008) 8958. doi:10.1364/OE.16.008958.

[15] S. Karimelahi, L. Abolghasemi, P.R. Herman, Rapid micromachining of high aspect ratio holes in fused silica glass by high repetition rate picosecond laser, Appl. Phys. A Mater. Sci. Process. 114 (2014) 91-111. doi:10.1007/s00339-013-8155-8.

[16] N. Muhammad, D. Whitehead, A. Boor, W. Oppenlander, Z. Liu, L. Li, Picosecond laser micromachining of nitinol and platinumiridium alloy for coronary stent applications, Appl. Phys. A Mater. Sci. Process. 106 (2012) 607-617. doi:10.1007/s00339-0116609-4.

[17] NIST, National Institute of Standards and Technology, https://physics.nist.gov/PhysRefData/FFast/html/form.html, last updated : 2005.

[18] J.M. Liu, Simple technique for measurements of pulsed Gaussian-beam spot sizes, Opt. Lett. 7 (1982) 196. doi:10.1364/OL.7.000196.

[19] J. König, T. Bauer, Fundamentals and industrial applications of ultrashort pulsed lasers at Bosch, Front. Ultrafast Opt. Biomed. Sci. Ind. Appl. XI. 7925 (2011) 792510. doi:10.1117/12.878593. 
[20] E.S. Dreier, C. Silvestre, J. Kehres, D. Turecek, M. Khalil, J.H. Hemmingsen, O. Hansen, J. Jakubek, R. Feidenhans'1, U.L. Olsen, Virtual subpixel approach for single-mask phase-contrast imaging using Timepix3, J. Instrum. 14 (2019) C01011-C01011. doi:10.1088/1748-0221/14/01/C01011. 